\title{
EL CONCEPTO DE CLÁSICO Y SU APLICACIÓN A LA LITERATURA ESPAÑOLA THE CONCEPT OF THE CLASSIC AND ITS APPLICATION TO SPANISH LITERATURE
}

\author{
ANTONIO CARREIRA \\ Centro para la Edición de Clásicos Españoles. CECE
}

\begin{abstract}
Resumen
En este trabajo se ofrece una reflexión sobre el concepto de lo clásico, siguiendo las consideraciones y argumentos de algunos célebres críticos como María Rosa Lida y, en especial, T. S. Eliot, y su aplicación a la Literatura española.

Palabras Clave: Clásico, T. S. Eliot, Rosa María Lida, Literatura española.
\end{abstract}

\section{Abstract}

This paper offers a reflection on the concept of the classic, following the considerations and arguments of some famous critics such as María Rosa Lida and, specially, T. S. Eliot, and its application to Spanish Literature.

Key Words: Classic, T. S. Eliot, Rosa María Lida, Spanish Literature.

Un escritor celebérrimo en su tiempo, Charles-Augustin Sainte-Beuve (18041869), publicó en 1850 un artículo titulado "Qu'est-ce qu'un classique?», en el cual, tras lamentar que Francia no haya tenido clásicos antes del siglo XVII - pues no concede ese título a Rabelais ni a Montaigne-, acaba reconociendo tales a Racine, Molière y La Fontaine. ${ }^{1}$ Advierte que no es bueno que un escritor parezca clásico a sus contemporáneos demasiado pronto, como les ocurrió a Fontanes o a Andrieux, escritores estimados en su tiempo que pocos recuerdan hoy. A continuación, el crítico se dedica a imaginar el templo del gusto literario, en cuya cúspide pone a Homero, seguido de Sófocles, Platón, Demóstenes, por supuesto Virgilio, Horacio, Dante,

\footnotetext{
* Recibido: 25-04-2020. Aceptado: 12-07-2020

${ }^{1}$ Charles Augustin Sainte-Beuve, OEuvres choisies, ed. de Victor Giraud, Paris, A. Hatier, 1934, pp. 519-523.
} 


\section{Antonio Carreira}

Cervantes y el mayor de los clásicos sin saberlo, que sería Shakespeare. Por desgracia, a pesar de su enunciado, el trabajo de Sainte-Beuve, una de sus causeries du lundi, apenas se ocupa del concepto de clásico, sino que más bien deriva hacia lo que en nuestros días ha hecho tanto ruido: el canon occidental. Su única ventaja respecto al de Harold Bloom es que, en lugar de dárnoslo hecho, aconseja que cada cual se forme el suyo propio.

No tendremos en cuenta un ensayo sin fecha de Italo Calvino que de alguna manera sugiere que cualquier autor difunto puede pasar por clásico. ${ }^{2}$ Siguiendo en orden cronológico, en 1944 publicó María Rosa Lida su Introducción al teatro de Sófocles, libro hermoso y profundo donde hay mucho que espigar. ${ }^{3}$ Lo primero, esta opinión de un colega algo más joven, el comediógrafo Frínico: «ßBienaventurado Sófocles, varón feliz y sabio, que murió después de larga vida, y de componer muchas hermosas tragedias! Bueno fue su fin y no padeció ningún mal.»4

A continuación, tras comparar a Sófocles con Esquilo y Eurípides, se pregunta por qué la obra de Sófocles, entre las del teatro antiguo, es hoy la única capaz de mantenerse en escena, y responde con una palabra: porque es clásica (p. 19). Esto la lleva a precisar cuáles son los principales rasgos de lo clásico:

1. El humanismo. El arte clásico se ocupa del hombre esencial cuyas condiciones son anteriores y superiores a las circunstancias cambiantes de cualquier ser humano.

2. La verdad u objetividad. «El arte clásico se encara con realidades, no con esperanzas ni con ensueños», dice textualmente, y añade algo que hemos de recordar más abajo: «En ese sentido no es clásica la Divina comedia», ni lo son la comedia española del Siglo de Oro o el cine actual, ambos con su inevitable justicia poética en el desenlace -lo que llaman happy ending los aficionados a decir las cosas en inglés.

3. El arte clásico es arte universal, no particular. No se ocupa de este hombre, aunque solo existen los hombres concretos, sino del hombre. Por eso la actividad artística es comparable a la científica, que partiendo de hechos singulares permite formular una ley general.

«Sófocles pinta solo lo que ve, y lo que ve alrededor suyo es el mal... Pinta realidades. Pinta la pena, no sabe nada del mito de la culpa» (p. 26), es decir, representa problemas sin pretender explicarlos. En resumen, la poesía griega es la más clásica de

\footnotetext{
${ }^{2}$ Italo Calvino, Por qué leer los clásicos, Madrid, Siruela, 2015.

${ }^{3}$ Buenos Aires, Losada.

${ }^{4}$ Según Plinio el viejo, VII, 53, habría muerto de alegría al conocer una nueva victoria suya en la escena (Lida, pp. 13-14).
} 
todas, y dentro de ella destacan Homero y Sófocles, «el más homérico de los trágicos». «Por eso - concluye la autora - es Sófocles popular en el momento clásico de Atenas, el siglo de Pericles, y por eso, pasado este siglo, reconoce su grandeza el filósofo clásico, Aristóteles» (p. 21).

Es posible que, de las notas mencionadas, la primera y la tercera -i. e., el humanismo y la universalidad - estén tan cerca una de otra que resulte arduo distinguirlas. Poco importa para nuestros fines. La viva inteligencia de María Rosa Lida deja claro en qué consiste el concepto de clásico, o al menos en qué consistió durante mucho tiempo, y cómo cabe aplicarlo con igual justicia a un filósofo, a un escultor - es tópica la comparación de Sófocles con Fidias - o incluso a todo un siglo.

A la vez que salía el libro de María Rosa Lida, pronunciaba T. S. Eliot su conferencia «¿What is a Classic?» en la Virgil Society de Londres, fundada en 1943. El texto se publicó como plaquette en $1945^{5}$, y fue recogido en 1957 en su volumen On Poetry and Poets, vertido al español dos años después. ${ }^{6}$ No sabemos hasta qué punto el nombre de Eliot, poeta y ensayista, es familiar a los estudiantes de hoy día, a pesar del premio Nobel que obtuvo en 1948. En todo el siglo XX no ha habido quizá crítico más influyente. Baste recordar que estudió con filósofos como Henri Bergson en París, Bertrand Russell y Jorge Santayana en Harvard; que, una vez instalado en Inglaterra, se hizo amigo de William B. Yeats, James Joyce, Virginia Woolf o Ezra Pound, entre otros escritores ilustres; y que en el mundo hispánico fueron sus admiradores poetas de talla: Luis Cernuda, Octavio Paz, Jaime Gil de Biedma o José María Valverde, estos últimos además traductores de sus obras.

Comienza Eliot recordando que la palabra clásico tiene varias acepciones, no todas positivas, según quien la emplee. Piénsese - añadimos - en el sintagma música clásica, que para algunos jóvenes equivale a música aburrida, latosa, o de funeral. Hay hasta una colección de discos titulada classicmania, término que habla por sí solo. Al margen de eso, Eliot advierte también una cosa obvia: «solo con mirada retrospectiva e histórica se puede reconocer a un clásico» (p. 52). En su opinión, la principal característica de lo clásico es la madurez, un concepto difícil de definir, y que se aplica tanto a los espíritus individuales como a las lenguas, las costumbres y las épocas, originando casos de discordancia. Menos palmaria resulta la madurez en la lengua, que Eliot cree más fácil de percibir en la prosa que en el verso, y equivale a una evolución hacia un estilo común. Prescindiendo ahora de los ejemplos que brinda con

\footnotetext{
${ }^{5}$ London, Faber \& Faber, editorial que dirigía el propio Eliot. Ese año se imprimió al menos dos veces, elegantemente impreso en papel de hilo y encuadernado en tela azul.

${ }^{6}$ Publicado también por Faber \& Faber. Lo tradujo María Raquel Bengolea, Buenos Aires, Sur, 1959. En este libro, por el que citamos con algún retoque, la conferencia ocupa las pp. 50-69.
} 
autores poco sonados de la literatura inglesa, podríamos proponer que tal madurez en la prosa castellana se da principalmente en la segunda mitad del siglo XVI, desde los anónimos del Lazarillo o el Viaje de Turquía, fray Luis de Granada, fray Luis de León, el padre Sigüenza, Mateo Alemán y otros hasta Cervantes. No le falta razón a Eliot cuando afirma que en la época siguiente a la clásica los recursos se agotan o se vuelven excéntricos, se aprecia más la originalidad, la afectación, y por tanto se inicia una etapa senil y decadente, algo bien visible en España a medida que avanza el siglo XVII.

En nuestra poesía del XVI las cosas cambian antes gracias al genio de Garcilaso, que recoge la precoz madurez de la poesía italiana y la transmite a sus seguidores: Camões, Silvestre, fray Luis de León, Herrera, Francisco de la Torre, san Juan de la Cruz, Aldana, y varios más hasta Medrano, Lope de Vega, los Argensola y Góngora, que se encuentra en la línea divisoria de los siglos y de los estilos. Más tarde Quevedo, gran poeta a ratos, cae en excesos que son ya síntoma de inmadurez, y aunque por otras vías circulan Villamediana, el conde de Salinas, el Dr. Salinas, Ulloa, Solís, etc., la suya es una poesía con más pasado que futuro, y así seguirá siendo hasta bien entrado el siglo XIX.

La madurez, para Eliot, es también conciencia de los predecesores, siempre que no opriman dando la sensación de que todo ha sido ya hecho. La literatura inglesa isabelina, según esto, no es aún madura ni puede llamarse clásica, solo muestra esa «apariencia temprana de madurez» que el Renacimiento hereda de la antigüedad: algo manifiesto en las últimas obras de Shakespeare. Su parecer, no poco atrevido, es que en inglés los autores más cercanos al clasicismo serían el dramaturgo William Congreve a fines del siglo XVII y el poeta Alexander Pope en el XVIII, una época de espíritu maduro pero que hoy se nos antoja estrecho y provinciano (pp. 53 y 57).

Por otra parte, Eliot distingue al clásico en relación con su propia lengua, del clásico universal o absoluto, cuyo prototipo sería Virgilio. No podemos olvidar que el texto que venimos comentando fue una conferencia pronunciada en la Vergil Society por su fundador y presidente, durante los horrores de la segunda guerra mundial y en un país mucho menos romanizado que el nuestro. Es como si el concepto de clásico se hubiese forjado a la medida de Virgilio, puesto que la madurez de espíritu exige historia y conciencia de la historia, una conciencia - insiste Eliot - que «no puede estar del todo despierta sino allí donde hay otra historia distinta de la del propio pueblo del poeta» (p. 59). Esa conciencia la tenían los romanos porque detrás de ellos estaba la civilización griega, y Virgilio fue uno de los que más contribuyeron a desarrollarla. Basta recordar los modelos de sus tres obras mayores: Homero, Hesíodo y Teócrito. La historia de Eneas muestra el parentesco entre dos culturas, su fusión impulsada por el destino, y ese destino al fin no es otro que la creación de Europa. Con Virgilio 
en Roma ocurrió lo mismo que con Shakespeare en Inglaterra o con Racine en Francia: que sus sucesores vivieron a la sombra de su grandeza. «El poeta supremo, clásico o no - comenta Eliot - , tiende a agotar el terreno que cultiva, de forma que este, tras dar cada vez cosechas más pobres, queda en barbecho durante varias generaciones» (p. 62). Disipadas hace mucho las brumas que entorpecían nuestra visión, a cualquiera se le ocurre que en España hubo al menos dos casos similares: uno, la creación de la novela moderna a cargo de Cervantes, y su no menos asombrosa desaparición hasta el siglo XIX. El otro caso ya lo hemos apuntado antes: Góngora, quien hizo madurar el lenguaje poético castellano hasta su plenitud, extrayendo de él todos los efectos que en potencia encerraba, una pleamar tras la que vino la resaca. Eliot menciona a Cervantes, no a Góngora, a quien no podría apreciar sino traducido, lo que, en un poeta de tan alto nivel formal, es muy grave. ${ }^{7}$ No obstante, algunas de sus conclusiones parecen escritas pensando en él; esta por ejemplo: «Toda gran obra poética tiende a imposibilitar la producción de obras igual de grandes en el mismo género». La sentencia, por triste que resulte, puede explicar que un autor como Quevedo prefiriera mantener oculta la mayor parte de su disforme obra poética mientras vivió, y a la vez explica el fracaso de quienes imitaron las Soledades o el Polifemo, en español y en portugués, a este o al otro lado del Atlántico. Lo cual no es quitar méritos a los poetas Domínguez Camargo, Gregório de Matos o sor Juana Inés de la Cruz, que hicieron muy buena labor de imitación, sino poner las cosas en su punto. Pero Eliot continúa implacable: «No solo todo gran poeta, sino también todo poeta auténtico, aunque menor, realiza de una vez y para siempre alguna posibilidad de la lengua, y con ello deja una posibilidad menos a sus sucesores... El poeta clásico agota, además de una forma, la lengua toda de su época». 8 Volviendo a nuestro país, las burlas al culteranismo, de las que Góngora casi siempre quedó exento, confirman lo dicho; el único camino era la imitación, y por él no se iba muy lejos, sino que terminó en las glosas y sobre todo en los centones, unos ejercicios de virtuosismo desprovistos de vigor poético, que sin embargo solo se practicaron con poetas clásicos: Virgilio, Garcilaso y Góngora precisamente, de igual manera que sobre ellos tres se hicieron los comentarios más eruditos desde el P. La Cerda hasta Salcedo Coronel. Lo que siguió, en el desierto poético del siglo XVIII, no necesita comentario. Si ahora cambiamos de género, no ha faltado quien achacase a influencia de Góngora la prosa amanerada que escriben Juan de Piña, Bocángel o el mismo Gracián, en la cual era imposible que la novela moderna tuviese continuidad. En el género dramático, los autores que cultivaron la comedia desde Lope de Vega hasta Calderón, ya hemos

\footnotetext{
${ }^{7}$ «Lo que no puede traducirse es el hechizo, la música de las palabras, y parte del significado, que está en la música», dice el mismo Eliot más adelante (p. 230).

${ }^{8}$ Pensamiento que Eliot reitera en su conferencia de 1950, «Lo que Dante significa para mí»: «Un poeta realmente supremo hace también que la poesía sea más difícil para los que le suceden por el simple hecho de su supremacía» (Criticar al crítico y otros escritos, trad. de Manuel Rivas Corral, Madrid, 1967, p. 176).
} 
visto por qué, sin perjuicio de su ocasional grandeza, no podían ser clásicos en sentido estricto. Como tampoco lo fue Dante - pese a la opinión de Eliot. «El clásico perfecto - dice ya cerca del final - será aquel en el cual esté latente, si no manifiesto, el genio completo de un pueblo... El clásico, dentro de sus limitaciones formales, debe expresar el máximo posible de toda la gama sentimental representativa del carácter del pueblo que habla esa lengua» (p. 65). A esa característica la denomina amplitud, que solo es universal cuando afecta por igual a otras literaturas. El innegable clasicismo de Goethe, por ejemplo, no representa toda la tradición europea, sino que es «un tanto provinciano», cosa que veremos luego con más detalle. Y continúa Eliot con esta frase algo chocante: «Es necesario volver a las dos lenguas muertas; es importante que hayan muerto, pues por su muerte hemos recibido nuestra herencia» (p. 66). Hay aquí tal vez un pequeño juego de palabras, porque herencia se puede recibir de muchos que han escrito en lenguas aún vivas, y no digamos influencia, que está por todas partes y una de cuyas manifestaciones es la intertextualidad. Pero a Eliot le interesaba en ese momento regresar a Virgilio, «a quien debemos nuestra norma clásica», un poeta que no es necesariamente el mayor, sino aquel cuya privilegiada situación, en el origen mismo del imperio romano, «concuerda con su destino» (ibid.). Resume esto último con frase lapidaria: «Es el símbolo de Roma; y lo que Eneas es a Roma, la antigua Roma lo es a Europa» (ibid.). Difícil sería decir más en menos palabras, e imposible entenderlas sin tener bien presentes la Eneida y la trayectoria de Roma. Virgilio es el modelo, nos da el criterio para no caer en el peor de los provincianismos, que no es el espacial sino el temporal, «un provincianismo - aclara - según el cual el mundo es propiedad exclusiva de los vivos, una propiedad de la que no participan los muertos» (p. 68). No hace falta subrayar lo actual de semejante denuncia, y no solo en el ámbito literario sino en otros, sin excluir el político: a algún ministro, si eso sirviera de algo, habría que recordarle la conclusión donde Eliot identifica lengua y cultura con estas palabras: «el torrente sanguíneo de la literatura europea es el griego y el latín» (ibid.), o, según dirá más adelante, «la supervivencia de la literatura europea depende de nuestra continua reverencia por nuestros antepasados» (p. 224). Sana advertencia que no es de exclusiva aplicación a la literatura, sino que podría haber evitado desastres en otros dominios: ahí está la música para probarlo.

Antes hemos aludido de pasada a Goethe. Diez años después de la anterior conferencia, Eliot pronunció en Hamburgo la titulada «Goethe as the Sage», que puede leerse en el mismo volumen, y conviene hacerlo, porque ambas se complementan. Tal vez incluso alguien recuerde el ensayo de 1959 en que Cernuda comenta, con cierta acritud, esta segunda conferencia. ${ }^{9}$ Eliot considera a Goethe «uno de los grandes

9 Luis Cernuda, «Goethe y Mr. Eliot», Poesía y Literatura, II (Barcelona: Seix Barral, 1964), pp. 149162. Según D. Harris y L. Maristany, el ensayo se publicó por primera vez en La Gaceta, núm. 68 (México, 
europeos» (p. 224), y esto lo basa en dos criterios: permanencia y universalidad; es decir, será gran poeta europeo aquel que siga interesando a generaciones sucesivas, que lo comprenderán y valorarán de modo diferente. En ese grupo Eliot da cabida a pocos, porque deja fuera a ingenios como Wordsworth o Hölderlin, grandes sin duda pero menos significativos para quienes no son sus paisanos; en cambio, admite a tres con total seguridad: Dante, Shakespeare y Goethe. Esto lo lleva a evocar los inmortales personajes creados por los dos últimos: Hamlet y Fausto, y es ahí donde se acuerda de Cervantes, porque a la exigua lista que forman con Ulises agrega don Quijote. Como asienta de forma rotunda: «cada uno de ellos es muy de su país, y sin embargo es compatriota de todos nosotros... Todos han contribuido a que el europeo se explique a sí mismo - función propia de tales figuras» (p. 226).

Eliot se diría que hace algo de trampa manteniendo a Dante entre los grandes europeos, mientras que regatea el título a Cervantes, «hombre - dice él- de un solo libro, por admirable que sea» (pp. 226-227). Fácil sería redargüir que, aparte de haber compuesto Cervantes novelas cortas y entremeses magistrales, pocos escritores habrá como Dante a quienes se recuerde por un solo libro, un viaje de ultratumba en el cual, si bien tuvo el acierto de elegir a Virgilio para guía, no deja de chocarnos hoy la resignación con que lo condena a permanecer en los círculos infernales por el delito de haber nacido antes de Cristo. Esto no lo dice Eliot, anglicano convencido, pero lo pensará más de un lector agnóstico, cosa que son cada vez más muchos europeos. La ideología de Dante, o la escatología propia de su tiempo, ha dejado de ser mayoritaria, se ha hecho inaceptable aun para muchos creyentes, y tales altibajos en la estimativa, al arrastrar consigo la condición de gran europeo, pueden relegar un buen poeta llámese Dante o san Juan de la Cruz - al limbo del provincianismo. Un provincianismo al que no es ajeno el mismo Eliot cuando afirma que «de las religiones reveladas, y de los sistemas filosóficos, hay que creer que uno es verdadero y los otros falsos» (p. 241), pues la tendencia actual más bien consiste en sospechar que ninguno de ellos contiene la verdad completa.

A los requisitos de permanencia y universalidad, que Eliot considera esenciales en el gran poeta europeo, añade ahora tres más: abundancia de producción, amplitud de intereses y unidad. Si la amplitud y la unidad son patentes en Dante y Shakespeare, como la abundancia en Shakespeare y en Goethe, la unidad del último solo se descubre si se admite esta curiosa definición: «lo que cada uno de ellos nos da es la Vida misma, el Mundo visto desde un punto de vista particular de una época europea particular y de un hombre particular de esa época» (p. 227). Algo que difícilmente se puede negar a los españoles ya mencionados, y a otros que los superan en amplitud de miras y de

abril de 1960); L. Cernuda, Prosa completa (Barcelona: Barral, 1975), p. 1551. 
obra, caso de Lope de Vega o Pérez Galdós, autores con toda probabilidad desconocidos o mal conocidos por Eliot.

Sigue el crítico proponiendo que el hombre más representativo de una época o nación no sea demasiado grande ni demasiado pequeño. Añade con cierto humor que si tomásemos a los tres grandes poetas de quienes se ocupa como representativos, sería para descubrir que no lo son, pues están por encima de su época, incluso pueden ser sus mayores críticos, precisamente porque son sabios, con sabiduría no mundana sino espiritual (pp. 231-232). Eliot afirma con rotundidad que la sabiduría es indefinible, ya que, según añade, «comprender lo que es la sabiduría significa ser sabio», pero algo después se atreve a intentarlo: «La sabiduría es un don natural de intuición, madurado y aplicado por la experiencia, para comprender la naturaleza de las cosas, las cosas vivas, por cierto, y más aún el corazón humano» (p. 236). Es obvio que Shakespeare o Goethe tenían mucho de esto; no lo es menos que varios ingenios españoles no les van en zaga. Eliot, en el segundo trabajo que estamos siguiendo, no usa la palabra clásico, se limita a examinar la sabiduría de los que considera grandes autores europeos por antonomasia. Sería tarea compleja dilucidar la relación entre ambos conceptos: el de sabio y el de clásico, porque hoy llamamos sabio más bien al especialista en materias inasequibles para el hombre común. Eliot en cambio habla de poetas cuya sabiduría todos podemos aceptar, que nos hacen sentirnos más sabios, o menos ignorantes, después de haberlos leído, porque - subraya - «es probable que el lenguaje de la poesía sea el más apto para transmitir sabiduría» (p. 241). «Es la sabiduría de la poesía, que de ningún modo se comunica si el lector no la siente como poesía» (p. 236).

Sería ligereza creer que lo dicho se reduce a un problema terminológico, aunque lo haya, porque las palabras son seres vivos y cambian de significado. La agudeza de Eliot le permite poner el acento en aspectos habitualmente inadvertidos por la mayoría de los lectores, sobre todo hoy, cuando una sólida formación humanista como la suya se ha hecho rara. Las obras de arte existen para que disfrutemos y aprendamos de ellas, pero en nuestros días el mismo concepto de arte se ha hecho problemático. Las normas establecidas por los grandes artistas del pasado - Homero, Sófocles, Virgilio; Bach, Mozart, Beethoven; Tiziano, Velázquez, Rembrandt-, y por quienes las siguieron, modificaron e hicieron fructificar, fueron conculcadas hace ya más de un siglo por las vanguardias, que primero inventaron otras, y más tarde prefirieron eliminarlas, extremo tras el cual el arte deja de serlo y da lugar al «todo vale», al desconcierto estético en que nuestra edad está sumergida; las normas nuevas y viejas, puesta en 
duda su validez, dejan de ser operativas. Reflexiones como las de Eliot nos ayudan a no caer en aquel provincianismo, mencionado antes, de quienes creen alegremente que vivimos en el mejor de los mundos, pues en cuanto al arte la verdad bien podría ser todo lo contrario. Si alguien lo duda, está en su derecho, a menos que le parezca ofensivo poner tachas a la época en que le tocó vivir, porque en tal caso la duda dejaría de ser legítima. El tiempo dará la respuesta correcta.

\section{BibLIOGRAFÍA}

Calvino, Italo, Por qué leer los clásicos, Madrid, Siruela, 2015.

CERnUdA, Luis, «Goethe y Mr. Eliot», Poesía y Literatura, II, Barcelona, Seix Barral, 1964. , Prosa completa, Barcelona, Barral, 1975.

ELIOT, Thomas Stearns, «¿What is a Classic?», London, Faber \& Faber, 1945; reimpr. On Poetry and Poets, London, Faber \& Faber, 1957 [traducción de María Raquel Bengolea, Buenos Aires, Sur, 1959, pp. 50-69]. «Lo que Dante significa para mí», Criticar al crítico y otros escritos, trad. de Manuel Rivas Corral, Madrid, Alianza, 1967.

LidA, María Rosa, Introducción al teatro de Sófocles, 1944, Buenos Aires, Losada.

Sainte-Beuve, Charles Augustin, CEuvres choisies, ed. de Victor Giraud, Paris, A. Hatier, 1934, pp. 519-523. 